\title{
Use of two-dimensional gel electrophoresis to differentiate morphospecies of Alexandrium minutum, a paralytic shellfish poisoning toxin-producing dinoflagellate of harmful algal blooms
}

\author{
Leo Lai Chan"1,, Ivor John Hodgkiss 1,3, Paul Kwan-Sing Lam4, \\ Jennifer Man-Fan Wan², Hong-Nong Chou ${ }^{5}$, John Hon-Kei Lum³, \\ Maria Gar-Yee Lo ${ }^{1}$, Abby Sin-Chi Mak', Wai-Hung Sit ${ }^{2}$ and Samuel Chun-Lap Lo ${ }^{3 *}$ \\ ${ }^{1}$ Department of Ecology and Biodiversity, The University of Hong Kong, Hong Kong \\ ${ }^{2}$ Department of Zoology, The University of Hong Kong, Hong Kong \\ ${ }^{3}$ Proteomic Task Force, Department of Applied Biology and Chemical Technology, \\ The Hong Kong Polytechnic University, Hong Kong \\ ${ }^{4}$ Department of Biology and Chemistry, City University of Hong Kong, Hong Kong \\ ${ }^{5}$ Institute of Fisheries Science, National Taiwan University, Taipei, Taiwan, ROC
}

Contamination of shellfish with paralytic shellfish poisoning toxins (PST) produced by toxic harmful algal blooms (HABs) have been negatively affecting the shellfish and aquaculture industries worldwide. Therefore, accurate and early identification of toxic phytoplankton species is crucial in HABs surveillance programs that allow fish-farmers to take appropriate preventive measures in shellfish harvesting and other aquaculture activities to overcome the negative impacts of HABs on human health. The identification of toxic dinoflagellates present in the water is currently a time-consuming operation since it requires skillful taxonomists and toxicologists equipped with optical and scanning electron microscopes as well as sophisticated equipment, for example, high-performance liquid chromotography-fluorescence detection. In this paper, a two-dimensional gel electrophoresis (2-DE)based proteomic approach was applied to discriminate between toxic and nontoxic strains of Alexandrium minutum. Variation in morphological features between toxic and nontoxic strains was minimal and not significant. Also, variation in 2-DE protein patterns within either toxic or nontoxic strains was low, but pronounced differences were detected between toxic and nontoxic strains. The most notable differences between these strains were several abundant proteins with $\mathrm{p}$ Is ranging from 4.8 to 5.3 and apparent molecular masses between 17.5 and $21.5 \mathrm{kDa}$. Groups of proteins, namely NT1, NT2, NT3, and NT4, were consistently found in all nontoxic strains, while T1 and T2 were prominent in the toxic strains. These specific protein spots characteristic for toxic and nontoxic strains remained clearly distinguishable irrespective of the various growth conditions tested. Therefore, they have the potential to serve as "taxonomic markers" to distinguish toxic and nontoxic strains within A. minutum. Initial studies revealed that the expression pattern of T1 was tightly correlated to toxin biosynthesis in the examined alga and may be used to serve as a potential toxin indicator.

\section{Keywords:}

Alexandrium minutum / Harmful algal bloom species / Paralytic shellfish poisoning / Paralytic shellfish poisoning toxin / Two-dimensional gel electrophoresis
Received: May 4, 2004

Revised: August 12, 2004 Accepted: September 10, 2004
Correspondence: Dr. Samuel C.L. Lo, Proteomic Task Force, Department of Applied Biology and Chemical Technology, The Hong Kong Polytechnic University, Hong Kong, People's Republic of China

E-mail: bcsamlo@inet.polyu.edu.hk

Fax: $+852-23649932$
Abbreviations: PST, paralytic shellfish poisoning toxin; STX, Saxitoxin 


\section{Introduction}

Consumption of shellfish contaminated with paralytic shellfish poisoning toxin (PST) can lead to paralytic shellfish poisoning (PSP), a serious and potentially fatal illness. PSP is caused by a mixture of saxitoxin (STX) analogs of approximately two dozen naturally occurring cyclic perhydropurine compounds, which differ in their specific toxicities [1]. PSTs cause paralytic symptoms in an organism by acting as potent sodium channel blockers [2]. They are poisonous to higher levels of the food web [3] due to the accumulation in bivalves of a range of neurotoxins produced by several dinoflagellates, particularly those of the genera Alexandrium, Gymnodinium, and Pyrodinium. PSTs in shellfish and toxic microalgae have been determined by a variety of biological, biochemical, and chemical analytical procedures. Among them, biochemical (ELISA, receptor binding) and tissue culture bioassays [4] are superior to the mouse bioassay [5] or sophisticated chemical analytical alternatives (HPLC-FD [6], LC-MS [7], etc.) for routine toxin monitoring. The former are configured to yield extremely high sensitivity and specificity towards the target toxin analyte. However, limited availability of pure toxins commercially and the large variation in specificity of the antibody to individual toxins has hampered their application. Therefore, the use of HPLC with fluorescence detection is probably the most commonly employed chemical method for the sensitive and selective analysis of these compounds.

The increased distribution of PSP has become a global issue in parallel with the increase of algal blooms in frequency, intensity, and geographic distribution [8]. This illustrates the urgent need for early detection of harmful algal species in the water through continuous surveillance programs involving routine monitoring of toxic microalgae and regular screening of toxin levels in shellfish. At present, there is no convenient and economic method that can efficiently monitor, detect, and predict toxic algal blooms and PST production. Generally, morphological criteria have been sufficient to classify unicellular algae to species, and to identify potentially toxin-producing dinoflagellates. Difficulties arise, however, if morphological characteristics that distinguish one alga from the rest of the plankton community are lacking. For instance, some morphospecies have proven to be consistently linked to toxicity (e.g., A. catenella (Whedon and Kofoid) has been found to be constantly toxic), but other morphospecies such as A. tamarense (Lebour) Balech Taylor are known to exist in both toxic and nontoxic strains [9]. Considerable time and effort spent on traditional microscopy to differentiate these morphospecies have been wasted as they have identical morphology. To remedy these problems, identification methods that use a molecular probe such as oligonucleotides, which bind to complementary sequences of RNA or DNA from a specific species or group of species have been developed. They can be fluorescently labeled and used to visualize whole or intact cells [10]. Recently, another approach has been to separate individual cells from mixed plankton assemblages using magnetic beads and mono- clonal antibodies [11, 12]. However, these "hot-gun" antibodies raised against the overall surface antigens of a dinoflagellate, have been found to suffer from cross-reactions with non-target species and thus obstruct their use for the identification and isolation of toxic species in environmental samples. So far, much of the effort has been focused on development and characterization of antibodies or molecular probes for individual species and no single type of probe or assay strategy presently stands out as preferable over the others. Nevertheless, molecular probes are powerful tools for monitoring and research application, but more work is needed to compare and refine these different cell enumeration methods on field samples from specific regions. In the meantime, the use of proteomic procedures can be the simplest and fastest alternative to obtain strain- and species-specific 2-DE protein patterns for species recognition or strain differentiation within isolates of a single species [13].

Contamination of shellfishes by PST poses severe problems to aquaculture industries and public health due to consumption of toxic seafood [14]. Extensive work has been done on the ecology and physiology of STX biosynthesis in several PST-producing causative agents as well as monitoring and predicting outbreaks of blooms in coastal waters caused by these organisms. However, the molecular mechanism involved in toxin biosynthesis is virtually unknown. Studies using labeled precursors with A. tamarense and Aphanizomenon flos-aquae have indicated that PST is derived from acetate, arginine and methionine [15]. Several speculative pathways have been suggested for the biosynthesis of these unique tricyclic perhydropurine derivatives. Oshima [16] has found $\mathrm{N}$-sulphotransferase and $\mathrm{N}$-oxidase, which are reportedly involved in part of the PST biosynthetic pathway, in several dinoflagellates. However, direct precursors and specific enzymes and the full biosynthetic pathway of the toxins in toxin-producing dinoflagellates have not been defined and resolved as yet [17]. According to the work of TaroncherOldenburg et al. [18] in a toxic dinoflagellate A. fundyense, it was found that toxin biosynthesis was coupled to the $G_{1}$ phase of the cell cycle. They also found that observed variations in toxin content were a result of increasing periods of biosynthetic activity. Toxin content is generally high in the exponential growth phase, but decreases as cultures reach the stationary phase. Low temperature and low phosphate concentrations both result in increased cell toxicity, and nitrogen limitation may cause a decrease in toxicity. These studies describe general patterns of dinoflagellate toxicity, but the physiological or biochemical mechanisms underlying the observed variations remain unknown.

Antibodies to metabolically important proteins are being developed to study the physiology of phytoplankton [19]. Some examples include studying nitrogen fixation [20], iron stress [21], and phosphate stress [22]. However, the progress of using antibody probes to identify the cell-specific physiology of toxic phytoplankton is still limited. This is likely to be due to the difficulties involved in identifying and isolating target proteins and developing the immunoassays. 
In contrast to conventional biochemical approaches that monitored one or a few specific proteins at a time, proteomic analysis can monitor the expression of multiple proteins simultaneously. By comparing differential protein expressions of different stages of a toxic dinoflagellates and relate that to toxin production dynamics, proteins involved in toxin biosynthesis could be found. The complex toxin biosynthetic pathways and metabolic events in these toxic dinoflagellates may be deduced from the functions of identified proteins.

The goals of this study was to identify taxonomic biomarkers and/or potential toxin biomarkers to distinguish strains within A. minutum. Our results showed that characteristic spots identified in the established proteome reference maps with respect to toxic and nontoxic strains of A. minutum can be regarded as potential taxonomic biomarkers for strain differentiation. Initial studies revealed that the expression pattern of $\mathrm{T} 1$, a protein found in a toxic strain, was tightly correlated to toxin biosynthesis in the examined alga and may be used to serve as a potential toxin indicator. The method described here provides an important first step in elucidating features that may serve as biomarkers of toxicity on other toxic dinoflagellates.

\section{Materials and methods}

Unless stated otherwise, all chemicals were purchased from Sigma (St. Louis, MO, USA). All solvents were at least of AR grade while most were of HPLC grade.

\section{$2.1 \quad$ Cultivation of $A$. minutum}

\subsubsection{Experimental cultures of different clones of A. minutum grown under optimal conditions}

Nonaxenic cultures of eight clones of A. minutum (including five toxic (AMKS2, AMKS3, AMKS4, AMTK4, and AMTK7) and three nontoxic (AMTK3, AMTK5, and AMTK6) strains) were obtained from the Institute of Fisheries Science, National Taiwan University, Taipei, Taiwan, ROC. The strains of AMTK and AMKS of A. minutum were isolated from the TungKang (TK) and Kaohsiung (KS) areas of Taiwan, respectively. These unialgal isolates were batch-cultured in $\mathrm{K}$ medium [23] at $20^{\circ} \mathrm{C}$ under a $12: 12 \mathrm{~h}$ light: dark photoperiod at a light intensity of approximately 100-150 $\mu \mathrm{mol}$ photons $\mathrm{m}^{-2} \mathrm{~s}^{-1}$ provided by fluorescent lamps in a Conviron growth chamber (Model S10H; Conviron Controlled Environments, Winnipeg, Canada) for $14 \mathrm{~d}$ until the midexponential growth phase was reached with a growth rate $(\mu)$ of 0.2 . The growth rate $(\mu)$ was estimated from cell counts in the exponential phase using the formulation of Guillard [24]:

$\mu=\left(\frac{\operatorname{In} C_{1} 2 \operatorname{In} C_{0}}{T_{1} 2 T_{0}}\right)$

where $C_{0}$ and $C_{1}$ indicate the cell numbers at time $T_{0}$ and $T_{1}$, respectively.

\subsubsection{Cultivation of two representative strains of A. minutum over a 5-d period, under nutritional and environmental stresses for proteomic and toxicity analysis}

AMKS2 and AMTK3 were selected to represent the toxic and nontoxic strains of A. minutum, respectively, and were examined over a 5-d period after the midexponential growth phase had been reached as well as under light-, nitrogen-, or phosphate-limited growth to search for a set of candidate proteins, which may be concurrent with the PST production patterns. Axenic cultures of toxic and nontoxic strains of A. minutum were also generated to exclude the potential contamination caused by bacterial proteins on the expression of these candidate proteins.

\subsubsection{Cultivation of $\boldsymbol{A}$. minutum over a 5 -d period}

Batch cultures of AMKS2 (toxic strain) and AMTK3 (nontoxic strain) of $A$. minutum were prepared by inoculating $1 \mathrm{~L}$ of exponentially growing cultures into $10 \mathrm{~L}$ of $\mathrm{K}$ medium and these were grown as described in Section 2.1.1. Exponentially growing cultures of A. minutum were synchronized by a dark-induced block/release method [26]. Synchronization of the experimental cultures was achieved by maintaining the cells in continuous darkness for $72 \mathrm{~h}$. The cells were then entrained to the same photoperiod regime of $12 \mathrm{~L} / 12 \mathrm{D}$ as the light was turned on and the first sample was collected immediately at 8 am of day 1 . These representative cultures were sampled over a 5-d period at circadian times separated by $12 \mathrm{~h}$ [i.e., 8 am (light-on) and 8 pm (light-off), everyday] since $A$. minutum grew at the rate of 0.20 divisions $\mathrm{d}^{-1}$ in optimal environmental and nutritional conditions [25].

\subsubsection{Cultivation of $\boldsymbol{A}$. minutum under nutritional and environmental stresses}

The cultures for different conditions were prepared as follows:

1. The "seed population" was concentrated by centrifugation at $1000 \times \mathrm{g}$ for $15 \mathrm{~min}$ at $22^{\circ} \mathrm{C}$ (himac CR 22f, Hitachi high-speed refrigerated centrifuges, (Tokyo, Japan) at the midlog of the exponential growth phase (about day 14) and the pellets were rinsed twice with sterilized seawater to avoid any carry-over of nitrogen, phosphorous, or inhibitors in the inoculum.

2. The light-limited cultures were prepared by inoculating the seed population into normal $\mathrm{K}$ medium to achieve an initial cell density of $1 \times 10^{6}$ cells $/ \mathrm{L}$ and were maintained in continuous darkness for $72 \mathrm{~h}$.

3. The nitrogen-limited and phosphorous-limited cultures were prepared by inoculating the seed population into nitrogen-limited and phosphorous-limited K medium, respectively, to achieve an initial cell density of $1 \times 10^{6}$ cells $/ \mathrm{L}$ and the cultures were incubated at normal dark/light photoperiods. The cell densities were constantly monitored by 
counting at least 200 cells in a Sedgwich-Rafter counter twice a day using a compound microscope (Olympus BX 50; Olympus, Tokyo, Japan) until the stationary phase was reached. Experimental cultures continued to grow in nutrient depleted medium for another $72 \mathrm{~h}$ before harvested for proteomic analysis. The purpose of using stationary phase cultures was to prevent carry-over and ensure that all nitrogen and phosphorus in the inoculum had been used up and the growth was limited either by phosphate or nitrate.

4. Axenic culture of strains of AMKS2 and AMTK3 of A. minutum were established by inoculating the cells into the culture medium, which was supplemented with an antibacterial mixture of $100 \mathrm{U} / \mathrm{mL}$ penicillin and $100 \mu \mathrm{g} / \mathrm{mL}$ streptomycin (GIBCO BRL antibiotics, cat. no. 15140-122, $100 \mathrm{~mL}$ ) for several generations and mass cultures for analysis were made by growing the cells in $5 \mathrm{~L}$ flask with $3 \mathrm{~L}$ of $\mathrm{K}$ medium supplemented with the antibacterial mixture as mentioned above.

\subsection{Preparation of extract for proteomic analysis and HPLC-FD analysis}

Approximately, $1 \times 10^{6}$ A. minutum cells were collected by centrifugation at $5000 \times \mathrm{g}$ for $20 \mathrm{~min}$ at $22^{\circ} \mathrm{C}$ (himac CR $22 \mathrm{f}$, Hitachi high-speed refrigerated centrifuges) and the pellets were rinsed twice with sterilized seawater to avoid any carryover of culture medium. The pelleted cells were then kept in a $-80^{\circ} \mathrm{C}$ freezer for subsequent analysis. No sample was stored for more than 3 months.

\subsubsection{Protein extraction and quantification}

Water-soluble proteins were isolated as previously described [13]. Briefly, with a Microtip-probe sonifier (Model 250; Branson Ultrasonics, Danbury, CT, USA), cells were lysed in $0.5 \mathrm{~mL}$ of $40 \mathrm{~mm}$ prechilled $\left(4^{\circ} \mathrm{C}\right)$ Tris buffer at $\mathrm{pH} 8.7$ containing $30 \mathrm{U}$ of endonuclease (benzonase isolated from S. marcescens; Sigma E8263). Cell debris and unbroken cells were removed by centrifugation at $22220 \times \mathrm{g}$ for $15 \mathrm{~min}$ at $4^{\circ} \mathrm{C}$ (Mikro 22R, Hettich, Germany). The supernatants were concentrated by ultrafiltration through an Amicon YM-3 membrane (Amicon, Bedford, MA, USA) following the manufacturer's instructions. Protein quantification was performed by the Bradford assay (Bio-Rad, Hercules, CA, USA) [26].

\subsubsection{Toxin extracts from cultures of the toxic strains of $A$. minutum}

The pelleted cells were homogenized in $0.03 \mathrm{~m}$ glacial acetic acid with a Microtip-probe sonifier (Model 250, Branson Ultrasonics). Samples were chilled on ice between bursts of less than $10 \mathrm{~s}$. Cell debris and unbroken cells were removed by centrifugation at $22220 \times \mathrm{g}$ for $15 \mathrm{~min}$ at $4^{\circ} \mathrm{C}$ (Mikro
22R). The supernatants were filtered with a molecular-sieve membrane with a 10000 Da cutoff (YM-10 membrane; Amicon) following the manufacturer's instructions. The analytical procedures as described by Oshima [24], for quantification of analogs of PST: gonyautoxin I, II, III, IV (GTX1-4) were used. This methodology involved the use of a post-column HPLC derivatization coupled with fluorescence detection. The HPLC system was from Waters USA. A stainless-steel column of RP packing (Inertsil C8, $3 \mu$, $150 \mathrm{~mm} \times 4.6 \mathrm{~mm}$ and Inertsil C8, $5 \mu, 7.5 \mathrm{~mm} \times 4.6 \mathrm{~mm}$ all-guard cartridge; Alltech, USA) was used. Seven millimoles periodic acid in $50 \mathrm{~mm}$ potassium phosphate buffer ( $\mathrm{pH}$ 9.0) was used as the oxidizing reagent and $0.5 \mathrm{~m}$ acetic acid as the acidifying reagent. To achieve the separation of closely related toxin peaks, an isocratic elution with a mobile phase of $2 \mathrm{~mm}$ sodium 1-heptanesulfonate in $10 \mathrm{~mm}$ ammonium phosphate ( $\mathrm{pH}$ 7.1) was used. GTX1/4 and GTX2/3 standards were purchased from the National Research Council of Canada (NRC). The detection limits for individual toxins were determined to be: $17 \mathrm{ng}$ for GTX1; $4 \mathrm{ng}$ for GTX2; 4 ng for GTX3; 10 ng for GTX4. Variability was found to be less than $10 \%$. A $60-72 \%$ recovery was usually found. Concentrations were not corrected for recovery rates.

For dinoflagellate samples, the net toxicity per cell (pg STX eq./cell) was calculated as the sum of the toxicities contributed by individual toxins: Toxicity contributed by individual toxin $=$ [volume of extract $(\mathrm{L}) /$ number of cells $(106)$ extracted] $\times$ concentration of toxin $(\mu \mathrm{mol} / \mathrm{L}) \times$ specificity toxicity ( $\mu \mathrm{g}$ STX eq./ $\mu \mathrm{mol})$. The toxicity values used were recommended by Sullivan and Wekell [27], where the following values provided good correlation between mouse bioassay and HPLC results: C1/C2-47, B2-27, B1-27, GTX1346, GTX4-346, GTX2-182, GTX3-291, neosaxitoxin-364, and STX-364 (all expressed in $\mu \mathrm{g}$ STX equivalent to $1 \mu \mathrm{mol}$ ).

\subsection{Immobilized pH gradient 2-D PAGE}

Forty micrograms (analytical run) or $400 \mu \mathrm{g}$ (preparative gel for mass spectrometric analysis or $\mathrm{N}$-terminal amino acid sequencing) of each sample was mixed with a rehydration buffer before being loaded onto IPG strips of linear $\mathrm{pH}$ gradient 4-7 (Amersham Biosciences, Hong Kong, China) for subsequent staining with silver or CBB R-250, respectively. Rehydration, IEF and equilibration were performed as previously described [13]. Subsequently, SDS-PAGE was performed and proteins on the 2-DE gels were (1) visualized by silver staining for pattern comparisons; (2) electro-transferred onto a PVDF membrane for $N$-terminal amino acid sequencing, and (3) staining with CBB R-250 for MALDI-TOF MS. Three 2-DE gels were performed for each condition. Unless stated otherwise, the gels shown are representative of the three gels performed. Protein spots were selected for quantitative analysis if they have the potential to serve as a taxonomic biomarker or toxin biomarker and were consistently visible in all samples from one condition. The density of each 
spot was measured using an ImageScanner equipped with ImageMaster (Amersham Biosciences) software. The abundance of each spot was calculated as a percentage of the total density of all 720 and 643 spots measured on each gel for toxic and nontoxic strains, respectively.

\subsection{MALDI-TOF MS and $\boldsymbol{N}$-terminal amino acid sequencing by Edman degradation}

Protein spots were selected to determine the PMF by a MALDI-TOF MS (Autoflex; Bruker Daltonics, Leipzig, Germany) if they have the potential to serve as a taxonomic biomarker or toxin biomarker and were consistently visible in all samples from one condition. Selected protein spots were digested in gels according to the method described by Shevchenko et al. [28]. The digests were desalted with Zip Tip (Millipore, Boston, MA, USA) and subjected to analysis by MALDI-TOF MS. Calibration of the instrument was performed with internal standards, namely angiotensin, substance $\mathrm{P}$, bombesin, trypsin autolysis fragment, and adrenocorticotropic hormone with the respective monoisotopic masses at 1046.5, 1347.7, 1620.8, 2211.1, 2465.1. For each sample, spectra from 150 shots at several different positions were combined to generate a PMF. PMF obtained for each protein of interest was searched against the NCBI nonredundant database using the search engine MASCOT available at http://www/matrixscience.com. The search was limited with a mass tolerance of $\pm 0.2 \mathrm{Da}$. One missed cleavage per peptide was allowed and cysteines were assumed to be carbamidomethylated with acrylamide adducts and methionine in oxidized form. The minimum number of peptides required for each match was four.

Unidentified proteins were further characterized by $N$ terminal amino acid sequencing. Proteins separated by 2-D PAGE were electro-transferred onto PVDF membranes as previously described [29]. Selected protein spots were excised and subjected to $\mathrm{N}$-terminal amino acid sequencing using a Procise 492 cLC Model 610A protein sequencer (Applied
Biosystems, Hong Kong, China). Amino acid sequences obtained were searched against either the Protein Data Bank (PDB) or Swiss-Prot by BLAST. Settings for querying short sequences for nearly exact matches of peptide were used.

\section{Results}

\subsection{Morphology, PST profiles, and 2-DE protein patterns of different isolates of $\boldsymbol{A}$. minutum under optimal conditions}

Unialgal cultures of eight strains of the dinoflagellate A. minutum were divided into two categories according to their toxicity, namely toxic and nontoxic strains. Using Balech [30] as the standard for taxonomy of Alexandrium, the following characteristics, especially small cell size, narrow sixth precingular plate, and wide posterior sulcal plate, indicated all these isolates were A. minutum. Variation in morphological features between the two categories was minimal and not significant (Fig. 1). Some of the strains are known to be toxic, while others are nontoxic. The toxicities of various strains were confirmed by examining a subsample of individual cultures by instrumental analysis using HPLC. The toxin components of different toxic strains of A. minutum were found to be gonyautoxin 1-4 only (Fig. 2). These different toxic strains of $A$. minutum show a wide range of absolute toxicities: AMTK7, AMKS-2, and AMKS-3 are dominated by GTX-3 and GTX-2 with a small amount of GTX-4 and GTX-1, while AMTK4 contained trace and almost equal amounts of GTX-3 and GTX-2 in addition to the two major toxins GTX-4 and GTX-1. AMKS-4 contained small amounts of GTX-4 and GTX-1 and medium amounts of GTX-3 and GTX-2 when compared with other clones. On the other hand, strains AMTK-3, AMTK-5, and AMTK-6 were found to be constantly nontoxic as no toxins were detected by instrumental analysis using HPLC.
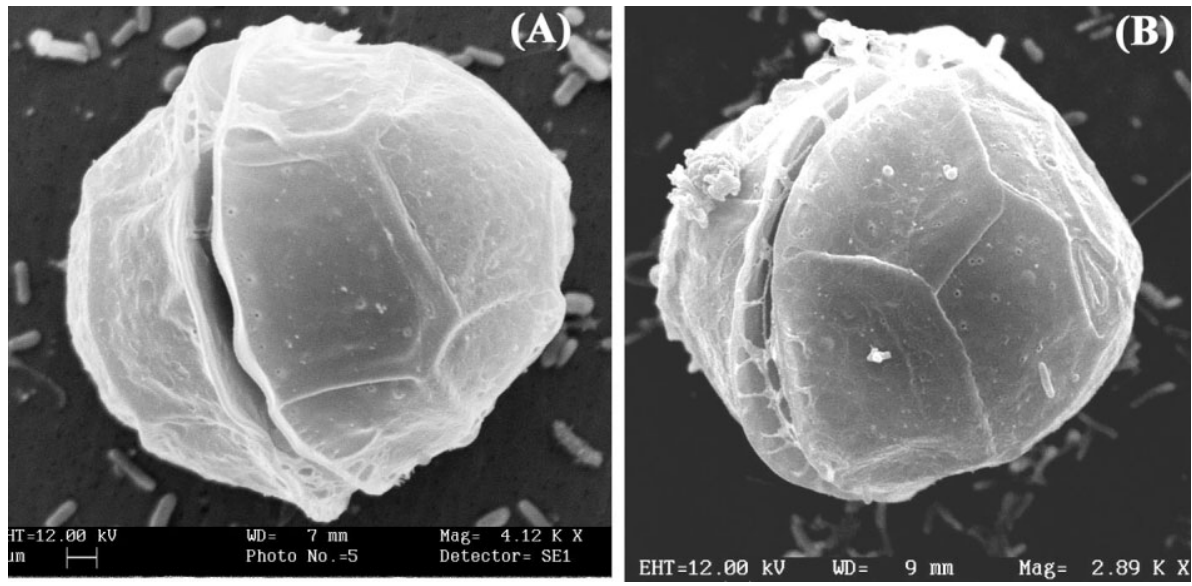

Figure 1. Scanning electron micrographs of Alexandrium minutum: (A) toxic strain, AMKS2; (B) nontoxic strain, AMTK3. 


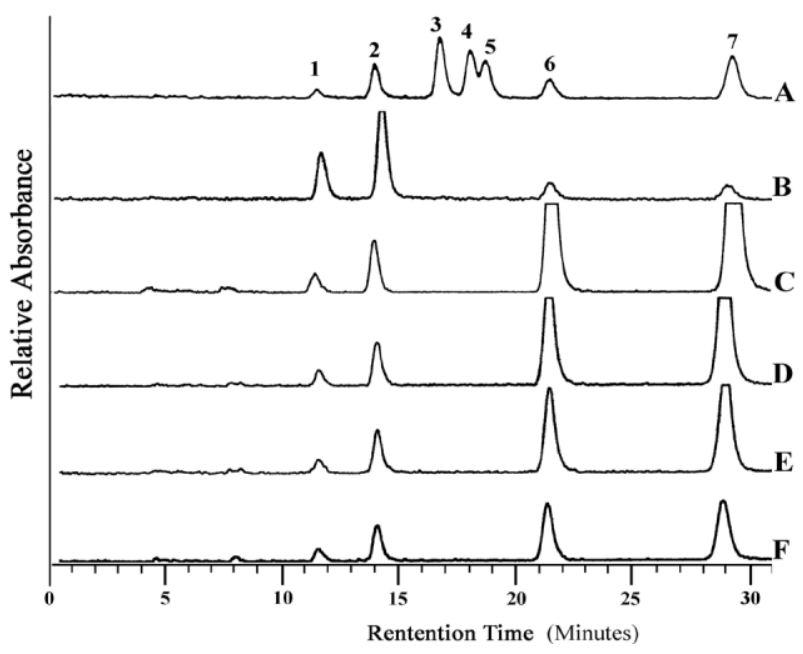

Figure 2. HPLC of PSP toxin profiles of: (A) standard mixture $(1=\mathrm{GTX} 4,2=\mathrm{GTX} 1,3=\mathrm{dcGTX} 3,4=\mathrm{B} 1,5=\mathrm{dcGTX} 2,6=\mathrm{GTX} 3$, and $7=\mathrm{GTX} 2$ ); and five toxic strains of Alexandrium minutum: (B) AMTK4, (C) AMTK7, (D) AMKS2, (E) AMKS3, (F) AMKS4, analyzed using a Cosmosil 5C18-AR column, $250 \mathrm{~mm} \times 4.6 \mathrm{~mm}$, a mobile phase of $0.05 \mathrm{M}$ phosphate buffer $(\mathrm{pH}=7.0)$ containing $2 \mathrm{~mm}$ HAS, and a flow rate of $0.8 \mathrm{~mL} / \mathrm{min}$.

Proteome reference maps were established for the toxic as well as nontoxic strains of A. minutum (Fig. 3). In general, we found strong similarities in gel patterns of the arrayed proteins between the strains of the same category, toxic or nontoxic. 2-D gels of different strains of the same category grown under the same conditions were superimposable. The distinct 2-DE protein patterns of toxic strains were readily discernable from the nontoxic strains. Therefore, proteome maps of AMKS2 (toxic) and AMTK3 (nontoxic) strains of A. minutum were selected as representative maps for these two categories and are shown in Fig. 4A and B, respectively, for easy comparison. A comparison of the 2-D maps of these two categories illustrates that they share a majority of proteins ( $\mathrm{ca} .75 \%$ of the spots in AMTK3 can be matched to AMKS2) judging in terms of the relative position of similarly grouped and shaped protein spots in gels (Table 1). Two hundred and thirty-three and 156 new spots were detected in the toxic and nontoxic strain, respectively. Among these new spots, significant differences were observed in several abundant proteins in these two categories. An abundant protein spot, T1 (with pI 4.9 and an apparent molecular mass of $20 \mathrm{kDa}$ ) and a cluster of proteins, T2 (with pI 5.5 and apparent molecular masses between 17.5 and $20 \mathrm{kDa}$ ), were consistently found in all toxic species (Fig. 4A). On the other hand, several abundant proteins, NT1 (with pI 4.7 and an apparent molecular mass of $20 \mathrm{kDa}$ ), NT2 (with pI 4.7 and an apparent molecular mass of $19 \mathrm{kDa}$ ), NT3 (with pI 4.8 and an apparent molecular mass of $19 \mathrm{kDa}$ ) and a pair of proteins, NT4 (with pI 5.4 and apparent molecular masses between 17.0 and $22 \mathrm{kDa}$ ), were only detected in the non-


Figure 3. 2-DE protein profiles of $40 \mu \mathrm{g}$ soluble proteins of $A$. minutum extracted with $40 \mathrm{~mm}$ Tris base from: (A) toxic strain AMKS2; (B) toxic strain AMKS3; (C) toxic strain AMKS4; (D) toxic strain AMTK4; (E) toxic strain AMTK7; (F) nontoxic strain AMTK3; (G) nontoxic strain AMTK5; and (H) nontoxic strain AMTK6. 
Table 1. Comparison of spot numbers from 2-DE reference maps of AMKS2 (toxic) and AMTK3 (nontoxic) strains of A. minutum

\begin{tabular}{lll}
\hline Strains & AMKS2 & AMTK3 \\
\hline Total number of spots & 720 & 643 \\
Spots common to reference gel (\%) & 720 & 487 \\
Spots new to reference gel (\%) & - & 156
\end{tabular}

Details of these gels are shown in Fig. 4 and AMKS2 was used as reference gel. toxic strains (Fig. 4B). Since the location and intensity of T1 and NT3 were very close, a composite gel (Fig. 4C) was obtained by applying equal amounts of water-soluble proteins of toxic and nontoxic strains. Regions enclosed by circles in Fig. 4B and $\mathrm{C}$ are expanded in the upper and lower portions of Fig. 4D, respectively. T1 and NT3 were confirmed to be two different protein spots with minute differences in apparent molecular masses and $\mathrm{pIs}$. The separate identities of T1 and NT3 were also confirmed with a combination of MALDI-TOF MS, enzyme digestion, and Edman sequencing for internal sequences. In addition, apparent basic
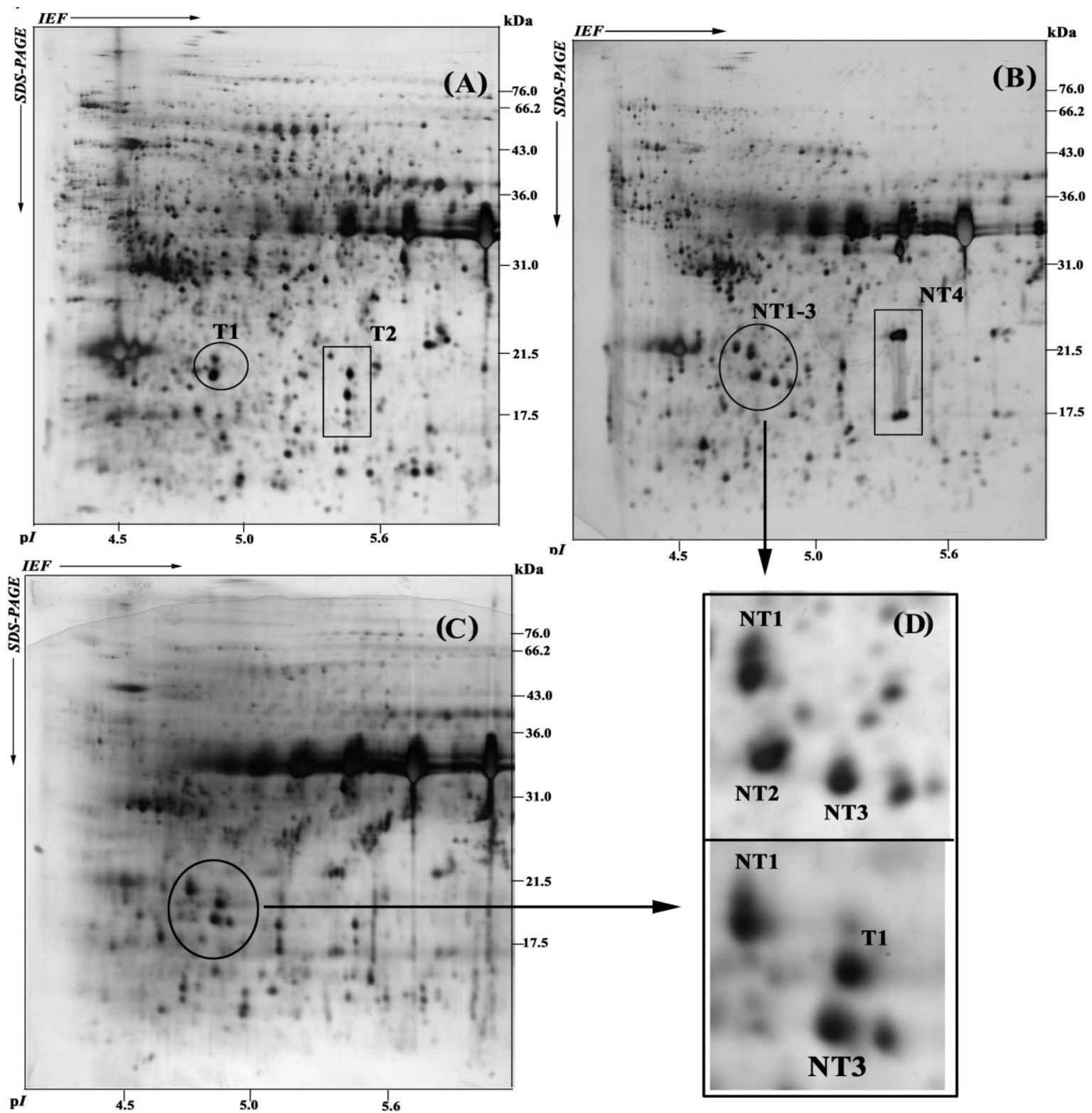

Figure 4. 2-DE protein profiles of $40 \mu \mathrm{g}$ soluble proteins of $A$. minutum extracted with $40 \mathrm{~mm}$ Tris base from: (A) toxic strain AMKS2; (B) nontoxic strain AMTK3; (C) composite 2-DE protein profiles obtained by loading $40 \mu \mathrm{g}$ soluble proteins of AMKS2 and AMTK3, respectively. T1, T2, and NT1-4 were found in toxic (T) and nontoxic (NT) strains, respectively. Regions enclosed by circles in (B) and (C) are expanded and detailed in upper and lower portions of (D), respectively, as indicated by arrows. 
shifts in a series of highly abundant protein spots of apparent molecular mass of $35 \mathrm{kDa}$ were observed in the toxic strains (Fig. 3A-E) when compared to the nontoxic strains (Fig. 3F-H).

\subsection{Dynamics of STX production and differential 2-DE protein patterns in $A$. minutum under different growth phases and different nutritional and environmental stresses}

\subsubsection{Dynamics of STX production}

In our study, the total culture toxin concentrations of AMKS2 strain (toxic) of A. minutum closely followed the cell concentration and growth phases, increasing throughout the entire experiment during the exponential phase between day 1 and day 5 in optimal growth conditions. The total toxicity on day 1,3 , and 5 is listed in Table 2 as AMKS2-1, AMKS2-3, and AMKS2-5, respectively. In nitrogen-limiting conditions (AMKS2-N), cells contained half as much toxin as those cultured under normal conditions (AMKS-1, AMKS-3, and AMKS-5). In contrast, toxin content in phosphorouslimited (AMKS2-P) and dark incubation (AMKS2-L) cultures increased significantly, compared with the nitrogen-limited culture (Table 2).

Table 2. Net total toxicity (pgSTXeq./cell) of toxic strain AMKS2 of $A$. minutum grown under different growth phases and growth conditions. (For calculation of the net total toxicity per cell (pgSTXeq./cell), please refer to Section 2.2.2.)

\begin{tabular}{lll}
\hline Sample & $\begin{array}{l}\text { Toxicity } \\
\text { (pgSTXeq./cell) }\end{array}$ & $\begin{array}{l}\text { Specific } \\
\text { growth rate }(\mu)\end{array}$ \\
\hline AMKS2-1 & 1.91 & 0.188 \\
AMKS2-3 & 2.68 & 0.240 \\
AMKS2-5 & 2.94 & 0.095 \\
AMKS2-N & 1.12 & -0.024 \\
AMKS2-L & 3.09 & -0.228 \\
AMKS2-P & 3.04 & -0.405 \\
AMKS2-AB & 2.35 & 0.210 \\
\hline
\end{tabular}

\subsubsection{Differential 2-DE protein patterns}

The possible effects of nutritional and environmental stresses and growth states on the expression of the protein spots characteristic for toxic and nontoxic strains were examined by analysis of the proteomic changes of two representative strains, the toxic strain AMKS2 and the nontoxic strain AMTK3 during a 5-d period as well as under dark incubation, phosphorous and nitrogen-limited growth. Exponentially growing batch cultures of AMKS2 (toxic strain) and AMTK3 (nontoxic strain) of A. minutum were sampled for $5 \mathrm{~d}$ at cir- cadian times separated by $12 \mathrm{~h}$ (i.e., 8 am and 8 pm everyday) since A. minutum grew at the rate of 0.20 divisions/d in optimal environmental and nutritional conditions and completed the whole cell-cycle in approximately $3.5 \mathrm{~d}$. The general 2-DE protein patterns of these samples were quite consistent in respect to different phases of the cell cycle. Therefore, three representative gels were selected for each category and are shown in Fig. 5. These characteristic spots, that is, $\mathrm{T} 1$ and T2; for toxic strain and NT4 for nontoxic strain, were consistently found in all phases of a growth cycle (Fig. 5A-H), while NT1, NT2, and NT3 appeared lower in day 1 (Fig. 5D and H. 1) and remained constant from day 3 to 5 (Fig. 5E-F and H. 2-H. 3).

The differentially expressed proteins in the two representative strains, AMKS2 and AMTK3, varied slightly under different environmental stresses and no major pattern of differences could be detected (Fig. 6). There is no visible difference in the level of T1 between dark incubation (Fig. 6B and I.2) and phosphorous-limited (Fig. 6C and I.3) growth cultures, whereas the level of T1 in nitrate-limited balanced growth cultures (Fig. 6A and I.1) appears lower than their counterparts. In contrast, the expression of NT1, NT2, and NT3 of the nontoxic strain of A. minutum remained constant under different stress conditions (Fig. 6E-G); the nutritional and environmental stresses had no apparent effect on their expression (Fig. 6J).

In some toxic algal cultures, bacteria living outside or inside the algal cells are either directly or indirectly associated with phycotoxin production [21]. Therefore, extracts prepared from axenic (AMKS2-AB) and nonaxenic cultures of A. minutum were compared in term of their toxicity and differential protein expression patterns. No significant differences were detected either in the total toxicity (Table 2) or differential protein patterns among the axenic (Fig. 6D and $\mathrm{H}$ ) and nonaxenic cultures (Fig. 5A and D).

\subsection{Protein identification by MALDI-TOF MS and $\mathrm{N}$-terminal amino acid sequencing by Edman degradation}

Tryptic digestion of 2-DE gel spots corresponding to NT1, NT2, NT3, and T1 produced several peaks. The six masses that shared among all spots were 858.65, 966.41, 1143.50, $1272.60,1494.00$, and $2615.50 \mathrm{~m} / z$. The four masses that differed among spots were 1259.00 and $2197.40 \mathrm{~m} / z$ produced by digestion of the T1 spot, $1479.0 \mathrm{~m} / z$ produced by the digestion of NT2 and NT3 and $2223.0 \mathrm{~m} / z$ produced by digestion of NT1, NT2, and NT3 spots (Fig. 7). Bioinformatic searches using PMFs obtained against NCBI nonredundant database, Swiss-Prot and TrEMBL databases revealed no similar protein in the database. Hence, further attempts to characterize these protein spots were performed using $\mathrm{N}$ terminal amino acid sequencing by Edman degradation. The $N$-terminal amino acid sequences of T1, T2, NT1, NT2, and NT3 are shown in Table 3. No discernible difference was detected in the first twenty-one amino acid sequences of T1, 



Figure 5. Selected 2-DE protein profiles of $40 \mu \mathrm{g}$ soluble proteins extracted with $40 \mathrm{~mm}$ Tris base from toxic strain AMKS2 cultures harvested at: (A) Day 1, (B) Day 3, and (C) Day 5; and nontoxic strain AMTK3 cultures harvested at: (D) Day 1, (E) Day 3, and (F) Day 5 of A. minutum in the exponential growth phase during a 5-d period in full $\mathrm{K}$ medium. Regions enclosed by circles in (A), (B), and (C) are expanded in (G.1), (G.2), and (G.3), respectively, highlighting changes of T1. Corresponding NT1-3 regions enclosed in (D), (E), and (F) are expanded in (H.1), (H.2), and (H.3), respectively.

NT1, NT2, and NT3, whereas discrepancies were detected in the $22^{\text {nd }}, 25^{\text {th }}, 27^{\text {th }}-28^{\text {th }}, 30^{\text {th }}$, and $32^{\text {nd }}-33^{\text {rd }}$ amino acids in their amino acid sequences. A comparison of the 35 amino acid sequences of these four proteins revealed that a similarity of $85.70,94.30$, and $91.43 \%$ could be assigned to NT1, NT2, and NT3, respectively with respect to T1. Searching using partial amino sequences against the Protein DataBank (PDB) and Swiss-Prot by BLAST revealed no similar protein in the database for these proteins, but T2 was identified as a chain M, peridinin-chlorophyll-protein.

\section{Discussion}

\subsection{Morphology, PST profiles, and 2-DE protein patterns of different isolates of $\boldsymbol{A}$. minutum under optimal conditions}

A commonly accepted paradigm in the study of STX-producing dinoflagellates is that the total concentration of all toxins (toxin content) in one isolate can vary with growth conditions, but that the relative abundance of each toxin (toxin composition) does not change [31]. The toxin profiles 



(E)


Figure 6. 2-DE protein profiles of $40 \mu \mathrm{g}$ soluble proteins extracted with $40 \mathrm{~mm}$ Tris base from (i) toxic strain AMKS-2 cultures of $A$. minutum grown in: (A) nitrogen-limited growth culture; (B) $72^{\text {nd }} \mathrm{h}$ of darkness for the dark incubation culture; (C) phosphorous-limited growth culture, and (D) nutrient enriched growth culture with an antibiotic mixture and (ii) nontoxic strain AMTK-3 cultures of $A$. minutum grown in: (E) nitrogen-limited growth culture; (F) $72^{\text {nd }} \mathrm{h}$ of darkness for the dark incubation culture; (G) phosphorous-limited growth culture; and (H) nutrient enriched growth culture with an antibiotic mixture of $100 \mathrm{U} / \mathrm{mL}$ penicillin and $100 \mu \mathrm{g} / \mathrm{mL}$ streptomycin. T1 regions enclosed by circles in (A), (B), (C), and (D) are expanded in (I.1), (I.2), (I.3), and (I.4), respectively. NT1-3 regions enclosed in (E), (F), (G), and (H) are expanded in (J.1), (J.2), (J.3), and (J.4), respectively.

Table 3. Comparison of amino acid sequences of proteins NT1, NT2, and NT3 from nontoxic strain, AMTK-3; and T1 and T2 from toxic strain, AMKS-2 of $A$. minutum by $N$-terminal sequence analysis. Boxes indicate the discrepancies in $\mathrm{N}$-terminal amino acid sequences between these four proteins. Shading indicates the two specific amino acids found in the amino acid sequences of T1

\begin{tabular}{|c|c|c|}
\hline $\begin{array}{l}\text { Proteins } \\
\text { spots }\end{array}$ & $N$-terminal sequence & $\begin{array}{l}\text { Matching protein } \\
\text { in database }\end{array}$ \\
\hline NT1 & $\begin{array}{l}\text { VSAEY LERLG PKDAD VPFTA } \\
\text { A A GG G E EPVV FDDRP }\end{array}$ & No \\
\hline NT2 & $\begin{array}{l}\text { VSAEY LERLG PKDAD VPFTA } \\
\text { A PGG P E HPVTF DKRP }\end{array}$ & \\
\hline NT3 & $\begin{array}{l}\text { VSAEY LERLG PKDAD VPFTA } \\
\text { A PGG P E HSVTFERP }\end{array}$ & \\
\hline $\mathrm{T} 1$ & $\begin{array}{l}\text { VSAEY LERLG PKDAD VPFTA } \\
\text { A PGGA E HPVTF TKRP }\end{array}$ & \\
\hline $\mathrm{T} 2$ & Eigda akklg dasya faxgv & $\begin{array}{l}\text { Chain } \mathrm{M} \text {, } \\
\text { peridinin-chloro- } \\
\text { phyll-protein }\end{array}$ \\
\hline
\end{tabular}

in the test alga were fairly consistent when cells were grown in optimal environmental and nutritional conditions. Different strains of A. minutum can be distinguished by their unique toxin profiles (different relative abundance of each toxin) and the toxin profiles of different strains of A. minutum in this study, in which GTX2 and GTX 3 are major components, is similar to that of A. minutum strains from Australia [32] and Spain [33]. In this study, proteomic analysis was carried out on five toxic and three nontoxic strains of A. minutum in order to search for taxonomic biomarkers for both categories (toxic and nontoxic) for strain differentiation. A comparison of the proteome reference maps generated for toxic and nontoxic strains revealed that variations in 2-DE protein patterns among toxic strains on one hand or among nontoxic strains on the other were minimal and not significant. However, pronounced differences in protein expression were seen when toxic strains were compared to nontoxic strains. Although they shared a majority of proteins ( $c a .75 \%$ of spots were similar judging in terms of the relative position of similarly grouped and shaped protein spots in gels), significant differences were observed in several abundant proteins, that is, NT1 to NT4 in nontoxic 



Figure 7. MALDI-TOF peptide mass map of the peptide mixture obtained from in-gel tryptic digestion of (A) T1 obtained from toxic strain AMKS-2; (B) NT1; (C) NT2; and (D) NT3 obtained from nontoxic strain AMTK-3 of Alexandrium minutum.

strains and T1 to T2 in toxic strains (Figs. 3, 4). Our results show that 2-DE-based proteomic approach can detect the presence of strain-specific proteins that may serve as taxonomic markers or toxin biomarkers for spe- cies and strain differentiation. The toxic strains and the morphologically similar nontoxic strains can be clearly distinguished by examination of their characteristic 2-DE protein patterns. 


\subsection{Dynamics of STX production and differential 2-DE protein patterns in A. minutum during different growth phases and under different nutritional and environmental stresses}

\subsubsection{Dynamics of STX production}

In nutrient replete cultures with no environmental stresses, toxin content peaked during the exponential growth phase with the fastest growth rate $(\mu)$, that is, 0.24 (Table 2). This result was in agreement with previous findings on Alexandrium spp. by Anderson et al. [34] that cells produced toxins at rates approximating those needed to maintain a certain amount of toxin in the daughter cells after each cell division. Enhancement in toxicity was also observed in phosphorousand light-starved cultures. General synthesis of major cellular components required for cell division, such as phospholipids, which are needed to make up novel cell membranes, and completion of DNA replication, both require the presence of phosphorous. Under suboptimal light conditions and phosphorous limitation, cell division ceased (i.e., $\mu$ $=-0.228$ and -0.405 for dark incubation and phosphorouslimited growth cultures, respectively) and protein synthesis was reduced. Lack of competition for intracellular free amino acids from metabolic pathways specific to cell division and general protein synthesis resulted in increased concentration of precursors and necessary enzymes for rapid toxin synthesis. Therefore, PST synthesis is promoted by phosphorous and light limitation. A dramatic decline in toxin production was observed in nitrogen-limited culture. Toxin production appeared to be nitrogen regulated and this is again in agreement with one popular speculation that toxins might be a nitrogen storage product ( $c a .33 \%$ of PST weight is $\mathrm{NH}_{4}^{+}$) [35] and toxin synthesis requires the availability of a source of nitrogen [36]. During nitrogen limitation, STX synthesis must compete for scarce nitrogen atoms with other essential $\mathrm{N}$-containing compounds resulting in a reduction of toxin production.

\subsubsection{Differential 2-DE protein patterns}

A comparison of the protein patterns during different phases of the cell cycle (Fig. 5) and under different nutritional and environmental stresses (Fig. 6) revealed that characteristic spots, T1 and T2 for toxic strains and NT 4 for nontoxic strains, are clearly distinguishable irrespectively of various growth conditions tested. They are stable properties neither transient characteristic during the growth stages nor response of the cells to external stresses.

The differentially expressed protein, $\mathrm{T} 1$, found in toxic strains, can be used as a "toxin indicator" to differentiate toxic strains from nontoxic strains within A. minutum. It is of particular interest with respect to its potential use as biomarkers of toxicity since its expressions (Fig. 5A-C and G) were found to be consistently in correlation with toxicity (Table 2) and seemed to be promoted by phosphorous and light stresses but depressed by nitrogen deficiency (Fig. 6A$\mathrm{C}$ and I). Monoclonal antibody raised against gel purified T1 is currently in progress and Western blot analysis will give more accurate representations of the relative abundance of T1 in relation to toxicity, which will give additional insight into its possible functional role in toxin biosynthesis.

The expression of NT1, NT2, and NT3 in a nontoxic strain of A. minutum increased from Day 1 to 3 (Fig. 5D-E) and then remained more or less constant (Fig. 5E-F). Nutritional and environmental stresses had no apparent effect on the expression of these proteins (Fig. 6E-G). The strongly coordinated synthesis of these three proteins with similar amino acid sequences could indicate they are probably transient highly abundant proteins of metabolic importance with similar function or they might be related to a specific phase of division of this alga. Thus there may be environmental factors that act to limit the production of these proteins to only certain phases of the daily cycle.

The association of bacteria with dinoflagellates has been a neglected field of study, which has gained prominence in recent years because of the possible role of bacteria in toxin synthesis. The presence of bacteria within dinoflagellates has been well-established [37], but their interaction with toxin synthesis still remains unknown. The toxin composition (Table 2) and differential protein expression profiles (Fig. 6D-H) obtained from the axenic cultures of A. minutum (AMKS2-AB) revealed no significant difference with their nonaxenic counterparts (Fig. 5A and D). These findings could possibly rule out bacterial involvement in toxin synthesis in this test alga. Evidence from others [44] indicated that toxins might be synthesized using nitrogen that is recycled within the cells, rather than solely using inorganic nitrogen recently taken into the cells. This suggests that bacteria co-existing inside A. minutum might represent a "self-sustaining" source of organic nutrition to the algae in a mutualistic fashion.

\subsection{Protein identification by MALDI-TOF MS and $N$-terminal amino acid sequencing by Edman degradation}

Since there is little genomic sequence data currently available for dinoflagellates, the characterization of these proteins by bioinformatics data mining are not currently possible. Four proteins, which are characteristic of different strains, were further characterized by a combination of MALDI-TOF MS and $N$-terminal amino acid. Mass spectrometric analysis revealed that T1, NT1, NT2, and NT3 shared similar PMFs, suggesting that these spots might be isoforms of the same proteins or closely-related proteins (Fig. 7A-D). The first 21 identical $N$-terminal amino acids between these four spots obtained by Edman degradation (VSAEYLERLGPKDADVP FTAA) together with the spectra in Fig. 7 suggested that these proteins were likely to have resulted from expression of the same gene. The mass differences indicated that they had undergone different translational or post-translational pro- 
cessing. However, discrepancies in $22^{\text {nd }}, 25^{\text {th }}, 27^{\text {th }}-28^{\text {th }}, 30^{\text {th }}$, and $32^{\text {nd }}-33^{\text {rd }}$ amino acids between these four spots thereby suggested that they had actually arisen from different gene products and resulted from pretranslational rather than translational or post-translational changes. The process of how these proteins were pretranslationally modified in toxic and nontoxic strains is a subject of ongoing interest. Nevertheless, the two masses (i.e., ca 1259 and $2197 \mathrm{~m} / z$, which were only found in the mass spectrum of peptide tryptic digest of T1 spot) and the two amino acids (i.e. alanine and serine of no. $25^{\text {th }}$ and $32^{\text {nd }}$ of the amino acids sequence of $\mathrm{T} 1$, respectively) were diagnostic of T1 compared to NT 1-3. Therefore, $\mathrm{N}$-terminal sequencing from a limited supply of starting materials or analysis by mass measurement alone is often not sufficient for determination of modified residues or for protein structural analysis. Sequence analysis of the modified peptide by nano-EST-IT MS or $N$-terminal microsequencing of protein by Edman degradation can be of added value. After a suitable amino acid sequence has been obtained, a cDNA-cloning project can be initiated. However, as mentioned previously, genomic data of A. minutum is almost completely lacking. The role of T1 in PST-toxin production remains unresolved until the successful cloning and the elucidation of the DNA sequence of T1. It should be stressed that the next logical step is validation of the role of $\mathrm{T} 1$ in toxin biosynthesis of toxin producing A. minutum or to identify/isolate similar proteins/genes in other PST-producing dinoflagellates.

\section{Conclusions}

A computer-aided analysis of 2-D protein gels combined with the characterization of proteins by MALDI-TOF MS and $N$ terminal sequencing is a powerful approach for a comparative study of the toxic and nontoxic strains of A. minutum. Toxic and nontoxic strains were readily discernable from a bird's eye view of the established proteome reference maps with respect to toxic and nontoxic strains of A. minutum. Different sets of peptide mass fragments, obtained from the taxonomic markers (i.e., NT1-3 in nontoxic strains and T1 in toxic strains of A. minutum), can be further used to elucidate the functionally significant structural modifications of these biomarker proteins, which might help to gain an understanding of the biochemical pathways operating in the dinoflagellates and the biosynthetic mechanism of the toxins. Since analysis was focused on these highly abundant proteins, it might be possible to monitor the toxic dinoflagellates qualitatively and quantitatively in seawater using antibodybased ELISA assays or rRNA-probe based whole-cell hybridization. Ultimately, such methods can be incorporated into autonomous devices so as to provide real time in situ monitoring of these toxic algal species to predict bloom development and movement.

The approach here, of identifying toxin-associated proteins through the use of 2-DE followed by physiological verification and characterization by a combination of $\mathrm{N}$-termi- nal sequencing by Edman degradation and MALDI-TOF MS analysis, may serve as a blueprint for similar work with other toxic species whose genomics are poorly characterized in the future.

This work is partially supported by a research grant from the Dean's reserve (FAST) of the Hong Kong Polytechnic University (Account no. 875D) awarded to SCL. The authors express their gratitude to Ms. Nicola Choi, Department of Department of Biology and Chemistry, City University of Hong Kong, for her assistance in analysis of the toxin contents for the tested alga and Kou Hing Hong Scientific Supplies Ltd., Hong Kong, for making a private donation to the department in supporting this work. Chan LL is a Ph.D. candidate of the Department of Applied Biology a Chemical Technology, The Hong Kong Polytechnic University (A/C: G-V986).

\section{References}

[1] Hall, S., Reichardt, P. B., in: Ragelis, E. P. (Ed.), Seafood Toxins, American Chemical Society, Washington, D.C. 1984, p. 113.

[2] Catterall, W. A., Ann. Rev. Biochem. 1986, 55, 953-985.

[3] Shimizu, Y., Chem. Rev. 1993, 93, 1685-1698.

[4] Jellett, J. F., Marks, L. J., Stewart, J. E., Dorey, M. L. et al., Toxicon 1992, 30, 1143-1156.

[5] AOAC Method 959-08, in: Official Methods of Analyses, Association of Official Analytical Chemists, Arlington, Virginia, 1990, 15th Ed., pp. 881-882.

[6] Sullivan, J. J., in: Hall, S., Strichartz, G. (Eds.), Marine Toxins: Origin, Structure, and Molecular Pharmacology, American Chemical Society, Washington 1990, pp. 66-77.

[7] Quilliam, M. A., Janecek, M., Lawrence, J. F., Rapid Commun. Mass. Spectrom. 1993, 7, 482-487.

[8] Hallegraeff, G. M., Phycologia 1993, 32, 79-99.

[9] Taylor, F., in: Smayda, T. J., Shimizu, Y. (Eds.), Toxic Phytoplankton Blooms in the Sea, Elsevier Science, New York 1993, pp. 81-86.

[10] Anderson, D. M., Identification of harmful algal species using molecular probes. Sixiéme Conference Internationale sur le Phytoplancton Toxique, Nantes, France, 18-22 October 1993.

[11] Vrieling, E. G., Anderson, D. M., J. Phycol. 1996, 32, 1-16.

[12] Adachi, M., Sako, Y., Ishida, Y., Nippon Suisan Gakkaishi/ Bull. Jap. Soc. Sci. Fish., 1993, 59, 327-332.

[13] Chan, L. L., Hodgkiss, I. J., Lo, S. C. L., Proteomics 2004, 4, 180-192.

[14] Kodama, M., in: Botana, L. M. (Ed.), Seafood and Freshwater Toxins: Pharmacology, Physiology, and Detection, Marcel Dekker, New York 2000, pp. 125-149.

[15] Shimizu, Y., Gupta, S., Prasad, A. V. K., in: Graneli, E. et al. (Eds.), Toxic Marine Phytoplankton. Proc. 4th Int. Conf. Toxic Marine Phytoplankton, Elsevier, New York, Amsterdam and London 1990, pp. 271-274.

[16] Oshima, Y., J. Assoc. Off. Anal. Chem. Intl. 1995, 78, P528P532. 
[17] Anderson, D. M., Sci. Am. 1994, 271, 52-58.

[18] Taroncher-Oldenburg, G., Kulis, D. M., Anderson, D. M., Limnol. Oceanogr. 1997, 42, 1178-1188.

[19] Palenik, B., Wood, A. M., in: Cooksley, K. E. (Ed.), Molecular Approaches to the Study of the Oceans, Chapman and Hall, London 1997, pp. 187-205.

[20] Currin, C. A., Paerl, H. W., Suba, G. K., Alberte, R. S., Limnol. Oceanogr. 1990, 35, 59-71.

[21] La Roche, J., Boyd, P. W., McKay, R. M., Geider, R. J., J. Phycol. 1996, 31, 520-530.

[22] Scanlan, D. J., Mann, N. H., Donald, K. M., Wilson, W. H. et al., Appl. Environ. Microbiol. 1997, 63, 2411-2420.

[23] Keller, M. D., Selvin, R. C., Claus, W., Guillard, R. R. L., J. Phycol. 1987, 23, 633-638.

[24] Guillard, R. R. L., in: Smith, W. L., Chanley, M. H. (Eds.), Culture of Marine Invertebrate Animals, Plenum Press, New York 1995, pp. 181-194.

[25] Bechemin, C., Grzebyk, D., Hachame, F., Hummert, C. et al., Aq. Microb. Ecol. 1999, 20, 157-165.

[26] Bradford, M. M., Anal. Biochem. 1976, 72, 248-254.

[27] Sullivan, J. J., Wekell, M. M., in: Kramer, D.E., Kiston, J. (Eds.), Seafood Toxins. ACS Symposium Series 262, Elsevier North Holland, New York 1987, pp. 357-371.
[28] Shevchenko, A., Wilm, M., Vorm, O., Mann, M. et al., Anal. Chem. 1996, 68, 850-858.

[29] Butt, Y. K. C., Lum, J. H. K., Lo, S. C. L., Planta 2003, 216, 762771.

[30] Balech, E., The genus Alexandrium halim (Dinoflagellata), Sherkin Island Marine Station, Sherkin Island, 1995, p. 151.

[31] Ogata, T., Ishimaru, T., Kodama, M., in: Okaichi, T. et al. (Eds.), Red Tides : Biology Environmental Science and Toxicology. Proc. 1st Int. Symp. Red Tides, Elsevier, New York 1987, pp. 423-426.

[32] Oshima, Y., Hirota, M., Yasumoto, T., Hallegraeff, G. M. et al., Nippon Suisan Gakkaishi 1989, 55, 925.

[33] Franco, J. M., Fernandez, P., Reguera, B., J. Appl. Phycol. $1994,6,275-279$.

[34] Anderson, D. M., Kulis, D. M., Sullivan, J. J., Hall, S. et al., Marine Biol. 1990, 104, 511-524.

[35] Loeblich, A. R. III., in: Spector, D. L. (Ed.), Dinoflagellates, Academic Press, Orlando 1984, pp. 299-342.

[36] Flynn, K., Jones, K. J., Flynn, K. J., Mar. Biol. 1996, 126, 9-18.

[37] Doucette, G. J., Kodama, M., Franca, S., Gallacher, S., in: Anderson, D. M., Cembella, A. D., Hallegraeff, G. M. (Eds.), Physiological Ecology of Harmful Algal Blooms, SpringerVerlag, Berlin 1998, pp. 619-647. 